\title{
DEVELOPMENT OF FATS BASED ON OLIVE OIL BY CHEMICAL INTERESTERIFICATION AND ITS UTILIZATION IN COOKIE PRODUCTION
}

\author{
D. KAÇAR ${ }^{a}, H$. ERINÇ ${ }^{b}$ and D. SIVRI ÖZAY ${ }^{c *}$ \\ ${ }^{a}$ Food Processing Department, Çaycuma Vocational School of Food and Agriculture, Bülent Ecevit University, \\ Zonguldak. Turkey \\ ${ }^{b}$ Department of Food Engineering, Niğde Ömer Halisdemir University, Niğde. Turkey \\ ${ }^{\mathrm{c}}$ Department of Food Engineering, Hacettepe University, Beytepe Campus 06800 Cankara/Ankara. Turkey
}

(Received: 26 March 2017; accepted: 20 June 2017)

Refined olive oil (ROO) was blended with tristearin (TS) and palm oil (PO) at two different ratios (ROO:TS:PO; 75:15:10 and 85:10:5) and chemical interesterification was performed in order to produce two interesterified fats (IF1 and IF2) with high unsaturated fatty acids and low trans fatty acids contents.

Solid fat content (SFC), slip melting point (SMP), and fatty acid composition were determined in IF1 and IF2; the values were compared to that of partially hydrogenated industrial cookie shortening (ICS). Higher SMP was measured in interesterified fats contaning $75 \%$ ROO (IF1) and lower SMP was obtained in interesterified fats containing $85 \%$ ROO (IF2). SFC values of interesterified ROO blended oils were lower than ICS. Interesterified fats were used for cookie production, and cookie quality parameters, including oxidation stability, were determined.

Results showed that hardness values of cookies were not affected by fat types and higher spread ratios and lighter colors were obtained. IF1 and IF2 had higher total oxidation values as compared to ICS.

Keywords: chemical interesterification, olive oil, cookie, quality

Semi-solid plastic fats called shortenings are the most important ingredients succeeding flour and sugar in cookie production. Textural characteristics of cookies are provided by their high fat content. Generally, cookies contain $10-30 \%$ shortening depending on the formulations. Shortening is a solid fat product that is commonly used in baking industry because of its plasticity. Shortening is normally produced by partial hydrogenation process of vegetable oils such as cottonseed, palm, palm seed, sunflower, safflower, peanut, soybean, and canola oils (O'Brien, 1998; Zoulias et al., 2002). Hydrogenation is the saturation of double bonds in fatty acids with hydrogen by using a catalyst. Hydrogenation increases the slip melting point (SMP) of the fat, decreases the iodine value, and forms a fat more solid and saturated. However, hydrogenation causes return of the remaining unsaturated fatty acids to trans forms, decreasing the amount of essential fatty acids. Trans fatty acids are responsible for high low density lipoprotein (LDL) cholesterol levels and bad total cholesterol to highdensity lipoprotein (HDL) cholesterol ratios causing arteriosclerosis. In addition, they are also associated with increased risk of breast cancer, disorders of the nervous system, colon cancer, diabetes, and allergy (Dinc et. al., 2014). Several studies showed that the major source of trans fatty acids in human diet is bakery products such as cookies, cakes, and breads (Norhayatr et al., 2011). Fats for human consumption should contain less than $1 \%$ of the total

\footnotetext{
* To whom correspondence should be addressed.

Phone: +90 31229762 11; fax: +90 31229921 23; e-mail: sivri@hacettepe.edu.tr
}

0139-3006 (C) 2018 Akadémiai Kiadó, Budapest 
fat as trans fatty acids according to the World Health Organization (WHO) and Food Agriculture Organization (FAO).

NoRHAyATI and co-workers (2011) determined total trans fatty acid content of local (packed) and imported biscuits as $0.35-4.83 \%$ and $0.45-2.90 \%$, respectively. They also reported high level $(51.6 \%)$ of trans fatty acid content in local unpacked biscuits. Trans fatty acids of cookies and cakes that are produced in Turkey were determined as $1-30 \%$ and $4.6 \%$, respectively (Daglioglu et al., 2002). Karabulut (2007) found trans fatty acid content of cookies in the range of $2.25-3.54 \%$.

Due to the adverse effect of trans fatty acids on health, interesterification process is widely used as an alternative of hydrogenation for the modification of oils. Interesterification is an acyl-rearrangement reaction on the glycerol molecule in a random manner without any change in chemical composition, and modifies the physico-chemical characteristics of oils and fats (Amir et al., 2012). No transformation and isomeration occur in fatty acids of interesterified fats, and the nutritional properties of the triglycerides of interesterified oils are superior compared to the fats produced by the hydrogenation (SEnANAyake \& SHAHIDI, 2005). Interesterification improves the desirable characteristics of the mixture of lipids and enables to produce fats with suitable plasticity, melting point, and fatty acid composition (DA SILVA et al., 2010). Although enzymatic interesterification is available, chemical interesterification is mostly used due to being a simple, cheap, and easy modification method. In chemical interesterification sodium methoxide is used as catalyst. It is relatively inexpensive, readily available, and is allowed to be used as an adjuvant in foods. Sodium methoxide is a toxic chemical and is involved in the "Inventory of Substances used as Processing Aids (IPA) Main List" in Codex Alimentarius Commission (2012). It is stated that the amount of residue should be $<1 \mathrm{ppm}$. Although there have been many studies in the literature about fat production by chemical interesterification method, no studies have been found on residue detection in fats and in foods produced with these fats. In related works, sodium methoxide was assumed to be removed by consecutive water washings.

Olive oil with its fatty acid content of 55-83\% monounsaturated fatty acid (oleic acid) and $3.5-21 \%$ polyunsaturated fatty acid (linoleic acid) is the member of the oleic-linoleic group oils, and has been reported to have beneficial effects on human health, such as lowering serum cholesterol levels, suppressing certain types of cancer, enhancing liver function, and reducing the effects of aging and heart disease. Many nutritionists have attributed that benefit to the high proportion of monounsaturated fatty acids (MUFA) and minor components such as polyphenols, antioxidants, sterols, etc. (BosKou, 2006; DA Silva et al., 2010). DinC and coworkers (2014) chemically interesterified olive oil and its blends $(25,50$, and $75 \%)$ with palm oil and produced zero-trans interesterified fats for use in cookie production. Oleic acid content increased with increasing olive oil content. Higher spread ratios were obtained in cookies produced with interesterified fats containing 50\% and 100\% olive oil. Lightness (L) and redness (a) values of the cookies decreased with olive oil addition, but yellowness (b) values were not affected.

In this study, the aim was to produce interesterified fats with high content of unsaturated fatty acids based on olive oil, with low trans fat contents for use in cookie production. Refined olive oil (ROO) was blended with tristearin (TS) and palm oil (PO) at two different ratios (ROO:TS:PO; 75:15:10 and 85:10:5), chemical interesterification was performed, and two interesterified fats (IF1 and IF2) were produced. Some physical and chemical parameters of interesterified fats and quality parameters of cookie samples were determined. 


\section{Materials and methods}

\subsection{Materials}

The commercially refined, bleached, and deodorized olive oil was purchased from a local market. Palm oil and tristearin were obtained from Ülker Biscuits A.Ş. (Ankara, Turkey). Industrial cookie shortening (ICS) used as standard was supplied by ETİ Gida Sanayi ve Tic. A.Ş. (Eskişehir, Turkey). A soft white wheat (cv. Eser) flour was used in cookie production.

\subsection{Interesterification procedure}

Interesterification reactions were carried out in a jacketed stirred-batch reactor (1 1) using a hot plate stirrer according to the method of Rousseau and MARANGONI (1999) with some modifications. Total $300 \mathrm{~g}$ of ROO, TS, and PO were mixed in the ratios of 75:15:10 (IF1) and $85: 10: 5$ (IF2), then the mixes were chemically interesterified for $50 \mathrm{~min}$ at $100{ }^{\circ} \mathrm{C}$ in the presence of the catalyst sodium methoxide $(0.5 \%)$ under vacuum, and the reaction was completed by adding citric acid. The reaction mixture was washed with $55^{\circ} \mathrm{C}(3$ times $\times 150$ $\mathrm{ml}$ ) water and transferred to a beaker. For removing residual water, sodium sulphate was added to the mixture and vacuum filtration was applied. After filtration, the interesterified fats were stored at $4{ }^{\circ} \mathrm{C}$.

\subsection{Fat analysis}

SMP of the samples were measured according to AOCS (2003) Official Method Cc 3-25. The solid fat content (SFC) was measured by low resolution pulsed NMR using Maran SFC (Resonance Instrument Ltd., Witney, UK) according to AOCS (2003) Official Method Cd 16b-93. Fatty acid methyl esters (FAMEs) were prepared according to IUPAC (1987) method. The fatty acid compositions including trans forms were determined by Shimadzu GC-2010 gas chromatograph equipped with DB23 $(60 \mathrm{~m} \times 0.250 \mathrm{~mm} \times 0.25 \mu \mathrm{m})$ capillary column and flame ionization detector (FID). The carrier gas was helium $\left(0.3 \mathrm{ml} \mathrm{min}^{-1}\right)$. The split ratio was 1:80. The working temperatures of the injector, column, and detector were 230, 195, and $240{ }^{\circ} \mathrm{C}$, respectively. FAMEs were identified by standard FAMEs.

Oxidative stability parameters (peroxide, conjugated dienes and trienes, $p$-anisidine values) were determined according to AOCS (2003) Offical Method Cd 8-53, Ti-1a-64, Cd 18-90. Total oxidation (TOTOX) value was calculated according to SHAHIDI and WANASUNDARA (2002).

\subsection{Flour analysis}

Wheat flour was analysed for ash (08-01) according to AACC (1990) Standard Methods. Protein content of the flour was determined by NIR Systems Model 6500 Scanning spectrophotometer (A Perstorp Analytical Company, USA). Wet gluten was determined according to AACC (1990) Method No:38-11. Water absorption and physical dough properties were determined using the Brabender Farinograph (Duisburg, Germany) according to AACC (1990) Method No: 54-21.

\subsection{Preparation of cookies and cookie analysis}

IF1, IF2, and ICS were used in the cookie production according to AACC (1990) Method No. 10-54 in duplicate. Dough was rolled out (sheeted with the help of a rolling pin) and cut 
using a circular die of $6.0 \mathrm{~cm}$ diameter. Cookies were baked at $205 \pm 2{ }^{\circ} \mathrm{C}$ for $11 \mathrm{~min}$ in a rotating electric oven (Şimşek Laborteknik Ltd. Şti., Ankara). After cooling of the cookies for $30 \mathrm{~min}$, diameter (D) and thickness (T) measurements were taken using a caliper. Spread ratio was calculated from the ratio of diameter and thickness $(\mathrm{D} / \mathrm{T})$. Colour values $\left(\mathrm{L}^{*}, \mathrm{a}^{*}\right.$, and $b^{*}$ ) were measured by Minolta Spectrophotometer CM-3600d (Japan). Breaking strength of the cookies was measured in a Texture Analyzer (TA-XTplus, UK) with 3-point bending rig (HDP/3PB). A crosshead speed of $10 \mathrm{~mm} \mathrm{~min}^{-1}$ with a load cell of $50 \mathrm{~kg}$ was used in the study. The span between the two platforms was $10 \mathrm{~mm}$. The force required to break cookies individually were recorded and average values were reported as fracture force.

\subsection{Statistical analysis}

The spread ratio, color, and texture values of cookies and sensory analysis results were statistically evaluated by one-way analysis of variance procedure using ANOVA at 5\% level of significance. The least significant difference (LSD) test was used to determine the differences among means. SPSS 11.5 programme was used for statistical analysis.

\section{Results and discussion}

\subsection{Fat analysis}

SMP value of ICS was determined as $41^{\circ} \mathrm{C}$. Higher SMP $\left(45^{\circ} \mathrm{C}\right)$ was measured in IF1 than in IF2 $\left(25{ }^{\circ} \mathrm{C}\right)$. SMP of palm stearin changes between $46.6-53.8{ }^{\circ} \mathrm{C}$. Thus, it could be explained with the higher percentage of palm stearin and lower percentage of ROO in IF1. DA Silva and co-workers (2010) showed that chemical interesterification decreased the SMP of all virgine olive oil and palm stearin blends. This was because of diminishing of $\mathrm{S}_{3}+\mathrm{S}_{2} \mathrm{U}$ triacylglycerol with the contribution of unsaturated fatty acids in olive oil after interesterification. SFC values at different temperatures determine important characteristics of fats like physical appearance, organoleptic properties, consistency, and stability (CRIADO et al., 2008; Riberio et al., 2009). SFC curves of IF1, IF2, and ICS are presented in Fig. 1, measured at different temperatures $\left(0,10,21.1,33.3\right.$, and $\left.40.6{ }^{\circ} \mathrm{C}\right)$. The SFC values of ICS, IF1, and IF2 were determined as $34.7 \%, 15.7 \%$, and $5.1 \%$ at $21.1{ }^{\circ} \mathrm{C}$, respectively. SFC values of IF1 and IF2 were lower than ICS due to low saturated fatty acid content. Addition of olive oil increased monounsaturated fatty acid percent and decreased SFC values. CRIADO and co-workers (2008) reported increase in SFC values with the increase of the ratio of the fully hydrogenated palm oil (HPO) in the blends of HPO and virgin olive oil. ALPASLAN and KARAALI (1998) suggested that enzymatically and chemically interesterified blends of olive oil and partially hydrogenated palm oil (30:70 and 40:60) could be used for commercial margarine production.

ICS had $45.92 \%$ palmitic acid content (results not shown). It is possible to say that palm oil was used in high amounts in the production of the ICS. In addition, other saturated fatty acids, such as lauric and myristic acid, contents of the ICS seemed to be higher than that of IF1 and IF2. In terms of stearic acid, IF1 and IF2 had higher stearic acid content. Due to the high amount of oleic acid in olive oil, oleic acid contents were quite high in IF1 and IF2 (with the value of $61.91 \%$ and $63.37 \%$, respectively) as expected. Monounsaturated (MUFA), polyunsaturated (PUFA), and trans fatty acid (TFA) contents of the fats were given in Table 1. Saturated fatty acid content was the highest (60.57\%) in ICS followed by IF1 $(27.43 \%)$ 
and IF2 (25.91\%). MUFA content was the highest (64.71\%) in IF2. The increase of olive oil content of the interesterified fats resulted in higher MUFA and lower PUFA contents (linoleic and linolenic acids) in IF1 and IF2.

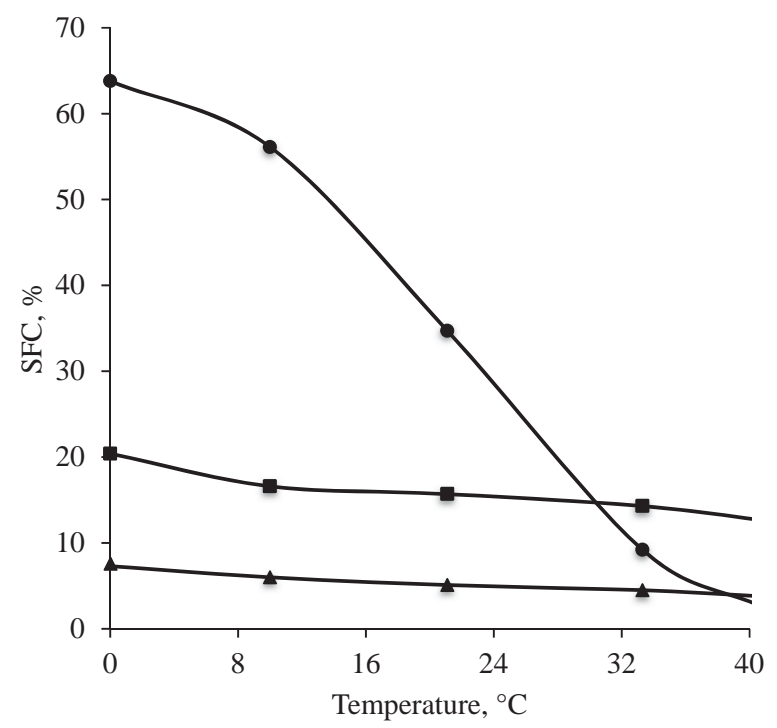

Fig. 1. Solid fat content curves of IF1, IF2, and ICS. ICS: Industrial cookie shortening; IF1: Interesterified fat 1: (ROO:TS:PO; 75:15:10); IF2: Interesterified fat 2: (ROO:TS:PO; 85:10:5)

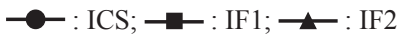

Table 1. Saturated, monounsaturated, polyunsaturated, and trans fatty acid values of industrial cookie shortening and interesterified fats (\%)

\begin{tabular}{lccc}
\hline & & Fat samples & IF2 \\
\cline { 2 - 4 } Fatty acids & ICS & IF1 & 25.91 \\
\hline Saturated & 60.57 & 27.43 & 64.71 \\
Monounsaturated & 28.12 & 62.89 & 8.86 \\
Polyunsaturated & 10.96 & 9.02 & 0.51 \\
Trans & 0.35 & 0.58 & \\
\hline
\end{tabular}

ICS: Industrial cookie shortening; IF1: Interesterified fat 1: (ROO:TS:PO; 75:15:10); IF2: Interesterified fat 2: (ROO:TS:PO; 85:10:5)

Trans fatty acid values $(0.58 \%$ and $0.51 \%$ for IF 1 and IF2, respectively) of olive oil based interesterified fats were higher than that of ICS, because of thermal oxidation of fats during interesterification reaction (MOYA MoReno et al., 1999). On the other hand, these fats could be labeled as "zero trans" according to Turkish Food Codex (2007). Dogan and coworkers (2007) produced chemically interesterified "zero trans" fats from cottonseed and palm oil (50:50).

The oxidative stability parameters of fat samples are given in Table 2. The highest peroxide value in IF 2 could be associated with higher ratio of polyunsaturated fats. Calculated 
TOTOX value of IF2 was higher than IF1. It suggests that IF2 with higher amount of monounsaturated fatty acid content made it more susceptible for oxidation than IF1. Conjugated diene, $p$-anisidine and TOTOX values were the highest in ICS. It could be concluded that oxidative stability analysis in IF1 and IF2 were performed right after interesterification.

Table 2. Oxidative stability of industrial cookie shortening and interesterified fats

\begin{tabular}{lccc}
\hline Oxidative stability parameters & ICS & IF1 & IF2 \\
\hline Peroxide value (meq O $2 / \mathrm{kg} \mathrm{fat)}$ & $3.3 \pm 0.04$ & $3.1 \pm 0.13$ & $3.9 \pm 0.34$ \\
Conjugated diene value $(233 \mathrm{~nm})$ & $0.17 \pm 0.011$ & $0.14 \pm 0.009$ & $0.15 \pm 0.004$ \\
$p$-anisidine value $(\mathrm{mMol} / \mathrm{kg} \mathrm{fat})$ & $5.40 \pm 0.132$ & $2.24 \pm 0.072$ & $1.38 \pm 0.043$ \\
TOTOX Value & 12.00 & 8.44 & 9.18 \\
\hline
\end{tabular}

Values are the mean of duplicates.

ICS: Industrial cookie shortening; IF1: Interesterified fat1: (ROO:TS:PO; 75:15:10);

IF2:Interesterified fat 2: (ROO:TS:PO; 85:10:5)

\subsection{Flour analysis}

Soft white winter (SWW) wheat flour (cv. Eser) used in cookie production had $0.67 \%$ ash, $11.9 \%$ protein, and $32 \%$ wet gluten contents. Farinograph water absorption of the flour was $53.0 \%$.

\subsection{Cookie analysis}

Colour values ( $\mathrm{L}^{*}, \mathrm{a}^{*}$, and $\mathrm{b}^{*}$ values) of cookies are given in Table 3 . According to this data, L (lightness) values of cookies produced with ICS were significantly higher than of the cookies produced with IF1 and IF2 ( $<<0.05)$. However, the difference between IF1 and IF2 was statistically not important. No significant difference was observed in a (redness) and $b$ values (yellowness) among the cookie samples.

Table 3. Quality characteristics of cookie samples produced by using industrial cookie shortening and interesterified fats

\begin{tabular}{lccc}
\hline Quality parameters & ICS & IF1 & IF2 \\
\hline Cookie L (lightness) value & $71.09^{\mathrm{a}}$ & $67.81^{\mathrm{b}}$ & $67.88^{\mathrm{b}}$ \\
Cookie a (redness) value & $6.99^{\mathrm{a}}$ & $7.08^{\mathrm{a}}$ & $6.96^{\mathrm{a}}$ \\
Cookie b (yellowness) value & $29.69^{\mathrm{a}}$ & $29.97^{\mathrm{a}}$ & $29.95^{\mathrm{a}}$ \\
Diameter (cm) & $7.72^{\mathrm{c}}$ & $8.08^{\mathrm{b}}$ & $8.24^{\mathrm{a}}$ \\
Thickness (cm) & $0.95^{\mathrm{a}}$ & $0.92^{\mathrm{ab}}$ & $0.91^{\mathrm{b}}$ \\
Spread ratio & $8.09^{\mathrm{c}}$ & $8.76^{\mathrm{b}}$ & $9.11^{\mathrm{a}}$ \\
Hardness value (N) & $6039^{\mathrm{a}}$ & $5508^{\mathrm{a}}$ & $6345^{\mathrm{a}}$ \\
\hline
\end{tabular}

Values are means of duplicate measurements. LSD: the least significant difference.

a,b,c: Means followed by different letter within each row are significantly different according to the LSD test $(\mathrm{P}<0.05)$ ICS: Industrial cookie shortening, IF1: Interesterified fat 1: (ROO:TS:PO; 75:15:10); IF2: Interesterified fat 2: (ROO:TS:PO; 85:10:5) 
Spread ratio $(\mathrm{D} / \mathrm{T})$ is one of the most important properties in cookie quality. Greater spread ratios are desirable and indicate a better cookie quality (SEKER et al., 2010). Diameter, thickness, and spread ratio values of cookies are given in Table 3. The highest diameter values were obtained from the cookies produced with IF2 $(\mathrm{P}<0.05)$. As the olive oil ratio in interesterified fats increased, the spread ratios also increased indicating better quality.

Textural properties of the cookies are given in Table 3. Cookies produced with IF2 had higher hardness values than cookies produced with IF1. Textural properties of cookies were comparable $(\mathrm{P}>0.05)$. This indicates that hardness values increased with the increasing olive oil content in formulation. It is well known that fat types (bakery fat, hydrogenated fat, margarine, and sunflower oil) have different effects on the quality of cookies, and cookies produced with oils have relatively harder texture due to poor entrapment of air during creaming (JACOB \& LEELAVATHI, 2006).

\section{Conclusions}

Olive oil based interesterified fat containing $85 \%$ olive oil with high amount of monounsaturated fatty acid $(64.71 \%)$ was produced by chemical interesterification. The amounts of unsaturated fat increased and saturated fat decreased with increase of olive oil content in interesterified fat formulation. It should be taken into account that a solid fat product having high amount of olive oil was produced, while in the market the maximum amount of olive oil in margarines produced with olive oil is $12 \%$.

The resulting interesterified fats had lower amounts of SFC when compared with ICS, and SMP of IF2 was found to be lower than IF1. Cookie texture was not affected by the fat type, and higher spread ratios were obtained in cookies produced with IF1 and IF2 compared with ICS.

It could be suggested that lower amount of olive oil (50-60\%) used in interesterified olive oil blends could result in harder fats with higher SFC values therefore better cookie quality could be obtained. Taken into consideration that two different interesterified "low trans" fat products containing olive oil at high rates were produced, it is possible to say these products have commercial potential in food industry.

This project was supported by The Scientific and Technological Research Council of Turkey (Tübitak TOVAG 108 O 586).

\section{References}

AACC (1990): American Association of Cereal Chemists, Approved methods of the AACC, 8th ed., the Association, St. Paul, MN., USA. Methods number 08-01, 38-11, 54-21, 10-54.

Alpaslan, M. \& Karaali, A. (1998): The interesterification-induced changes in olive and palm oil blends. Food Chem., 61, 301-305.

Amir, R.M., Shabbir, M.A., Khan, M.R. \& Husson, S. (2012): Interesterification of fats and oils - A review. Pak. J. Food Sci., 22(3), 143-153.

AOCS (2003): Official methods and recommended practices of the American Oil Chemists' Society, 4th ed., American Oil Chemists' Society, Champaign, IL, Methods Cc 3-25, Cd 8-53, Cd 16b-93, Cd 18-90, Ti-1a-64. Boskou, D. (2006): Olive oil chemistry and technology. AOCS Press, Illinois, p. 52.

Acta Alimentaria 47, 2018 
Codex Alimentarius Commission (2012): Inventory of substances used as processing aids (IPA), updated list (information document), Joint FAO/WHO Food Standards Programme Codex Committee on Food Additives, forty-fourth session, Available at ftp://ftp.fao.org/codex/meetings/CCFA/ccfa44/fa44_inf3e.pdf (last accessed 19 June 2017)

Criado, M., Hernandez-Martin, E., Lopez-Hernandez, A. \& Otero, C. (2008): Enzymatic interesterification of olive oil with fully hydrogenated palm oil: Characterization of fats. Eur. J. Lipid Sci. Tech., 110, 714-724.

da Silva, R.C., Soares, D.F., Lourenco, M.B., Soares, F.A.S.M., Silva, K.G., Goncalves, M.I.A. \& Gioielli, L.A. (2010): Structured lipids obtained by chemical interesterification of olive oil and palm stearin. LWT - Food Sci. Technol., 43, 752-758.

Daglioglu, O., Tasan, M. \& Tuncel, B. (2002): Determination of fatty acid composition and total trans fatty acids in cereal-based Turkish foods. Turk. J. Chem., 26, 705-710.

Dinc, S., Javidipour, I., Ozbas, O.O. \& Tekin, A. (2014): Utilization of zero-trans non-interesterified and interesterified shortenings in cookie production. J. Food Sci. Tech., 51, 365-370.

Dogan, I.S., Javidipour, I. \& AKan, T. (2007): Effects of interesterified palm and cottonseed oil blends on cake quality. Int. J. Food Sci. Tech., 42, 157-164.

IUPAC (1987): Standard methods for analysis of oils, fats and derivatives, International Union of Pure and Applied Chemistry, 7th ed., Blackwell Scientific Publications, IUPAC Method 2.301.

JACOB, J. \& LeELAVATHI, K. (2006): Effect of fat-type on cookie dough and cookie quality. J. Food Eng., 79, $299-305$.

Karabulut, I. (2007): Fatty acid composition of frequently consumed foods in Turkey with special emphasis on trans fatty acids. Int. J. Food Sci. Nutr., 58, 619-628.

Moya Moreno, M.C.M., Mendoza Olivares, D., amezquita Lopez, F.J., Gimeno Adelantado, J.V. \& Bosch Reig, F.B. (1999): Determination of unsaturation grade and trans isomers generated during thermal oxidation of edible oils and fats by FTIR. J. Mol. Struct., 482, 551-556.

Norhayati, M., Azrina, A., Norhaizan, M.E. \& Muhammad Rizal, R. (2011): Trans fatty acids content of biscuits commercially available in Malaysian market and comparison with other countries. Int. Food Res. J., 18, 1097-1103.

O’Brien, R.D. (1998): Fats and oils formulating and processing for applications. CRC Press, USA, 694 pages.

Riberio, A.P.B., Basso, R.C., Grimaldi, R., Gioielli, L.A. \& Goncalve, L.A.G. (2009): Effect of chemical interesterification on physicochemical properties and industrial applications of canola oil and fully hydrogenated cottonseed oil blends. J. Food Lipids, 16, 362-381.

Rousseau, D. \& Marangoni, A.G. (1999): The effects of interesterification on physical and sensory attributes of butterfat and butterfat-canola oil spreads. Food Res. Int., 31(5), 381-388.

Seker, I.T., Ozbas, O., Gokbulut, I., Ozturk, S. \& Koksel, H. (2010): Utilization of apricot kernel flour as fat replacer in cookies. J. Food Process Pres., 34, 15-26.

Senanayake, S.P.J.N. \& Shahidi, F. (2005): Modification of fats and oils via chemical and enzymatic methods. -in: Shahidi, F. (Ed.) Bailey's industrial oil and fat products. John Wiley \& Sons Inc., New York, pp. 555-584.

Shahidi, F. \& Wanasundara, U.N. (2002): Methods for measuring oxidative rancidity in fats and oils. -in: Aкон, C.C. \& Min, D.B. (Eds) Food lipids -Chemistry, nutrition and biotechnology. Marcel Dekker Inc., New York, pp. $483-506$

Turkish Food Codex (2007): Türk Gida Kodeksi Gida Maddelerinin Genel Etiketleme ve Beslenme Yönünden Etiketleme Kurallari Tebliğinde Değişiklik Yapilmasi Hakkinda Tebliğ, Tebliğ No: 40, T.C. Resmi Gazete, Sayi: 26622, Communiqué on the Amendment of the Communiqué on the Labeling Rules of the Turkish Food Codex for the General Labeling and Nutrition, Communiqué Number:40, Republic of Turkey Official Gazette, Issue: 26622 .

Zoulias, E., Oreopoulou, V. \& Kounalaki, E. (2002): Effect of fat and sugar replacement on cookie properties. J. Sci. Food Agr., 82(14), 1637-1644. 